\title{
MECHANICAL AND THERMAL PROPERTIES OF PLA BASED NANOCOMPOSITES WITH GRAPHENE AND CARBON NANOTUBES
}

\author{
Polya Angelova* \\ Institute of Mechanics (OLEM), Bulgarian Academy of Sciences, \\ Acad. G. Bonchev Str., Block 4, Sofia, Bulgaria
}

[Received: 18 April 2019. Accepted 08 July 2019]

doi: 10.7546/JTAM.49.19.03.04

\begin{abstract}
This work investigates thermal and mechanical properties of poly(lactic) acid (PLA) based composites with 6wt.\% graphene nanoplates (GNP) and multiwalled carbon nanotubes (MWCNTs), produced by melt extrusion. The crystallization increases, from amorphous for the PLA $(\sim 9 \%)$ to semicrystalline $(\sim 18 \%)$ for all nanocomposites with adding only $6 \%$ of filler compared with the pure polymer. Dynamic mechanical measurements in torsion show that in temperatures lower than $T_{g}$ (from -20 to $60^{\circ} \mathrm{C}$ ), when the material is in a solid state, the addition of a nanofiller, such as $6 \%$ graphene, results in an increase in storage modulus $G^{\prime}$ and loss modulus $G^{\prime \prime}$, which confirms the reinforcement effect of the nanofillers. We compare our material with the only one commercial benchmark filament Black Magic for 3D printing application with $14 \mathrm{wt} . \%$ graphene and carbon nanotubes.
\end{abstract}

KEY WORDS: biodegradable poly(lactic acid) nanocomposites, graphene, carbon nanotubes, loss modulus, storage modulus, thermal stability.

\section{INTRODUCTION}

With the increase of environmentally friendly materials, polylactic acid (PLA) has attracted a lot of interests from both industry and academia. Derived from renewable resources, PLA is valued for its biocompatibility, sustainability and biodegradability. In addition, PLA exhibits a high Young's modulus of around 3-4 GPa and a tensile strength of 50-70 MPa [1,2]. Hence, in comparison with commodity polymers such as polyethylene (PE), polypropylene (PP), polystyrene (PS) and polyethylene terephthalate (PET) [3], the modulus of PLA is quite attractive. One approach to improve the mechanical and thermal characteristics of PLA is through the addition of nanofillers [4-6]. Graphene or graphite nanoplatelets (GNPs) is a new carbon nanomaterial composed of stacked $2 \mathrm{D}$ graphene sheets with outstanding electrical properties (room-temperature electron mobility of $2.5 \times 10^{5} \mathrm{~cm}^{2} / \mathrm{Vs}$ ), thermal properties

\footnotetext{
${ }^{*}$ Corresponding author e-mail: p.angelova@imbm.bas.bg
} 
(thermal conductivity above 3,000 W/mK), and mechanical properties (Young's modulus of $1 \mathrm{TPa}$ and strength of $130 \mathrm{GPa}$ ) [7]. Therefore, graphene, including GNPs, is often hailed as the next generation multifunctional nanofiller for polymers [8,23]. These days a lot of polymer nanocomposites with GNP have been successfully prepared, including some GNP/PLA systems [7,9-12]. The structure and properties of these GNP/PLA composites have been studied with the main focus points being: 1) crystallization behaviour and kinetics [9-11, 13, 14]; 2) interface tailoring and morphology control $[12,15,16]$; 3) thermal and electric conductivity [16-20]; 4) mechanical properties, especially the reinforcing or toughening effect of GNP or graphene [19,21-23]; and 5) thermal degradation and biodegradation behaviour as well as other biological studies [22,24].

In the present study thermal analysis was used to understand the history of the samples - glass transition, crystallization and melting temperature but also to prove the thermal stability and degradation of our materials compared with benchmark filament Black Magic. In terms of mechanical properties, we obtained better elasticity and plasticity of the materials by adding only $6 \%$ nanofiller compared with the benchmark filament Black Magic that had 14\% of nanofiller.

\section{Materials ANd Methods}

\subsection{MATERIALS}

The polylactic acid polymer (PLA) Ingeo 3D850, prodused by Ingeo Biopolymer, NatureWorks, USA, was used for the melt extrusion. Graphene nanoplates (GNP) and multiwall carbon nanotubes (MWCNT) prodused by Times Nano, China, were used for preparation of nanocomposites.

Commercial Filament, benchmark "Black Magic", bought from Graphene 3D Lab, USA, is used as reference material. This filament is based on PLA, with $14 \%$ graphene and multiwalled carbon nanotubes, but no information on the type and characteristics is available.

The PLA types and different grades of GNP and MWCNTs are shown in Table 1.

Table 1. Typical properties of row materials used in this study

\begin{tabular}{ccc}
\hline \hline PLA 3D850 & TNIGNP & TNIMH4 \\
\hline Specific gravity $1.24 \mathrm{~g} / \mathrm{cc}$ & Number of layers $<30$ & Outer diameter $10-30 \mathrm{~nm}$ \\
MFI $\left(210^{\circ} \mathrm{C}\right)=7-9 \mathrm{~g} / 10 \mathrm{~min} ;$ & Median size $=5-7 \mu \mathrm{m}$ & Length: $10-30 \mu \mathrm{m}$ \\
Heat distortion $($ at $0.45 \mathrm{MPa})=80-90^{\circ} \mathrm{C}$ & Aspect ratio $\sim 240$ & Aspect ratio $>1000$ \\
\hline
\end{tabular}




\subsection{METHODS OF PREPARATION BY MELT EXTRUSION}

The nanocomposite hybrids were fabricated by melt compounding in a twin screw extruder at IPCB-CNR, Pozzuoli, Italy. Ten types of compositions, combining different proportions of GNPs and MWCNTs were produced at maximum $6 \mathrm{wt} \%$ filler contents. One kilogram in pellets were produced from each composition, including the neat PLA. The prepared pellets were further used at NanoTechLab (a spin-off company of the Institute of Mechanics, Bulgarian Academy of Sciences) for extrusion of filament for 3D printing.

The fillers and the polymer were dried before composite preparation. Two masterbatches of PLA-3D850 with $6 \mathrm{wt} \%$ TNIGNP and $6 \mathrm{wt} \%$ MWCNT-OH (Indus-

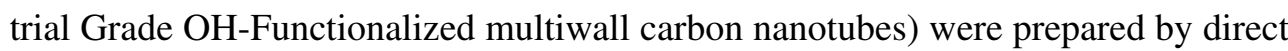
mixing of the filler and the polymer in a twin screw extruder (COLLIN Teach-Line ZK25T, Germany). Thermogravimetric analysis was used to analyze the filler concentration in the two masterbatches. The two- and three-component nanocomposites were processed by dilution of the two masterbatches with pure PLA-3D850 in appropriate proportions in the twin screw extruder, in the temperature range $170-180^{\circ} \mathrm{C}$ and screw speed of $40 \mathrm{rpm}$.

The concentration of the nanofiller was 1.5, 3 and $6 \mathrm{wt} \%$ of GNP, MWCNT and their combinations, and they are compared with pure PLA. The compositions prepared for this study are presented in Table 2.

Table 2. Compositions prepared for this study

\begin{tabular}{|c|c|c|c|}
\hline Samples & $\begin{array}{c}\text { Concentration of } \\
\text { GNPs } \\
\text { [wt } \%]\end{array}$ & $\begin{array}{l}\text { Concentration of } \\
\text { MWCNTs } \\
\text { [wt } \%]\end{array}$ & $\begin{array}{c}\text { Concentration of } \\
\text { PLA } \\
{[\mathrm{wt} \%]}\end{array}$ \\
\hline Pure PLA & 0 & 0 & 100 \\
\hline $6 \mathrm{wt} . \% \mathrm{GNP}$ & 6 & 0 & 94 \\
\hline 6 wt. $\%$ MWCNT & 0 & 6 & 94.0 \\
\hline 1.5 wt. $\%$ GNP/4.5 wt. $\%$ MWCNT & 1.5 & 4.5 & 94.0 \\
\hline 3 wt. $\%$ GNP/3 wt. $\%$ MWCNT & 3 & 3 & 94.0 \\
\hline 4.5 wt. $\%$ GNP/1.5 wt. $\%$ MWCNT & 4.5 & 1.5 & 94.0 \\
\hline Black magic & & & 86 \\
\hline
\end{tabular}

\subsection{METHODS OF CHARACTERIZATION:}

\subsubsection{DSC ANALYSIS (DSC Q20)}

DSC Q20 bought from the American company TA Instruments, was used for the thermal properties measurements. 
244 Mechanical and Thermal Properties of PLA Based Nanocomposites with ...

The experiments were carried out in an air atmosphere or in nitrogen.

The conditions under which the current DSC test was carried out were: a temperature range of $20^{\circ} \mathrm{C}$ to $200^{\circ} \mathrm{C}$ in a nitrogen atmosphere with a heating step of $20^{\circ} \mathrm{C} / \mathrm{min}$.

Degree of crystallinity $X_{c}$ was calculated by using equation [26]

$$
\% \text { crystallinity }\left(\% \chi_{c}\right)=\left(\frac{\Delta H_{m}-\Delta H_{c c}}{w \Delta H_{m}^{0}}\right) 100(\%),
$$

where $\chi_{c}$ is crystallinity $(\%), \Delta H_{m}$ is fusion enthalpy $(\mathrm{J} / \mathrm{g}), \Delta H_{c c}$ is cold crystallization enthalpy $(\mathrm{J} / \mathrm{g}), \Delta H_{m}^{0}$ is fusion enthalpy $(-93 \mathrm{~J} / \mathrm{g}$ ) when the crystallinity of PLA is $100 \%$ and $w$ is the portion of the polymer in the filled composites, $w=1$ for pure PLA and $w=0.94$ for $6 \%$ filler [26].

We used DSC analysis to study six samples with different concentration of GNP and MWCNT prepared by melt extrusion. The weight of the samples was around $10 \mathrm{mg}$. They were put in an aluminum pan and hermetically sealed in order to prevent gas emissions in the instrument or in the environment. Tests were performed in four cycles (two heating and two cooling scans) from $40^{\circ} \mathrm{C}$ to $200^{\circ} \mathrm{C}$, at $20^{\circ} \mathrm{C} / \mathrm{min}$. We heated the sample from room temperature to $200^{\circ} \mathrm{C}$, Ramp $20^{\circ} \mathrm{C} / \mathrm{min}$, and the sample was held at these conditions for 3 minutes. Second step - we cooled it down from $200^{\circ} \mathrm{C}$ to $40^{\circ} \mathrm{C}$ and again kept the sample for 5 minutes. After that we heated it again from $40^{\circ} \mathrm{C}$ to $200^{\circ} \mathrm{C}$ and left it for 5 minutes before the final cooling procedure. After the second heating we observed Run_2.

After these steps we could determinate $T_{g}, T_{c c}$ and $T_{m}$. Then we used the equation (1) to calculate the degree of crystallinity $X_{c}$.

\subsubsection{THERMOGRAVIMETRIC ANALYSIS (TGA Q50)}

TGA Q50 bought from the American company TA Instruments, was used for the thermal properties measurements.

The conditions under which the current TGA test was carried out are: heating the sample from $20^{\circ} \mathrm{C}$ to $500^{\circ} \mathrm{C}$ in a nitrogen atmosphere, with a heating step of $20^{\circ} \mathrm{C} / \mathrm{min}$.

The thermogravimetric analysis provides information on the thermal stability of the material as well as the effective amounts of the filler in the composite. This analysis is carried out under the following conditions: the sample is weighed $(\sim 10 \mathrm{mg})$ and placed in the pan. Weight loss is measured versus temperature. From the graph obtained, the following characteristics are defined: start of degradation $\left(T_{\text {onset }}\right)$; temperature at $10 \%$ loss of mass; peak of degradation $\left(T_{p}\right)$, and residual ash $(\%)$. The start of degradation $\left(T_{\text {onset }}\right)$ determines the thermal stability of the material, i.e. the temperature at which the material does not change its structure. The peak of degrada- 
tion is the temperature at which the material degraded and lost about $50 \%$ of its mass. The residual ash is determined at the heating temperature $\left(490^{\circ} \mathrm{C}\right)$ and it characterizes the amount of remaining material that could not degrade at this temperature. This is characteristic for the fillers since they require a higher temperature until their complete degradation compared to the pure PLA polymer, which completely degrades at about $400^{\circ} \mathrm{C}$. By the amount of residual ash, the amount of filler in the polymer composite can be determined.

\subsubsection{DMTA ANALYSIS}

An AR-G2 instrument (TA Instruments), was used to examine the mechanical properties. The experiment was performed under the following conditions: Dynamic Mechanical Thermal Analysis (DMTA) in torsion mode at $1 \mathrm{~Hz}$ frequency and $1 \mathrm{~N}$ force in a temperature range of $-20^{\circ} \mathrm{C}$ to $140^{\circ} \mathrm{C}$, with a heating rate of $3^{\circ} \mathrm{C} / \mathrm{min}$.

Through DMTA analysis in torision mode and $1 \mathrm{~N}$ force in a temperature range of $-20^{\circ} \mathrm{C}$ to $140^{\circ} \mathrm{C}$ were determined the following characteristics:

- Storage modulus $\left(G^{\prime}\right)$, which gives us information on the elasticity and the strength of material;

- Loss modulus $\left(G^{\prime \prime}\right)$, which gives us information on the plasticity of material;

- Tan(delta) which represents the ratio $G^{\prime \prime} / G^{\prime}$. The peak of $\tan ($ delta) corresponds to the glass transition temperature $\left(T_{g}\right)$.

For this study was used 3D printer bought from 3D Factories (LMB-Factories GmbH, Germany) with dimensions $400 \times 400 \times 500 \mathrm{~mm}^{3}$ (height $\times$ width $\times$ length) and working area of $200 \times 200 \times 230 \mathrm{~mm}^{3}$ (height $\times$ width $\times$ length) was used for this study. The nozzle size is up to $0.5 \mathrm{~mm}$ and temperature is up to $250^{\circ} \mathrm{C}$. Print speed: $80 \mathrm{~mm} / \mathrm{s}$ and printing density of the samples $100 \%$. The printed samples had the parameters: length $60 \mathrm{~mm}$, width $13 \mathrm{~mm}$ and thickness $3 \mathrm{~mm}$ (Fig. 1a) and they were printed using rectilinear pattern (Fig. 1b). This pattern creates a rectangular mesh, predefined at $45^{\circ}$ from the machine axis. Each following layer is perpendicular to the previous one, but at the same angle.

Four types of nanocomposites: pure PLA; $6 \%$ GNP; $6 \%$ MWCNT; and 3\% GNP/3\% MWCNT were produced and tested using these conditionals.

\section{Results And Discussion}

\subsection{DSC ANALYSIS FROM THE FIRST HEATING AND COOLING (RUN_1)}

In this study, the results of the DSC curves are the first step where we can define the thread - to determine the impact of the pre-history of the material associated with its obtaining and exploitation conditions. 

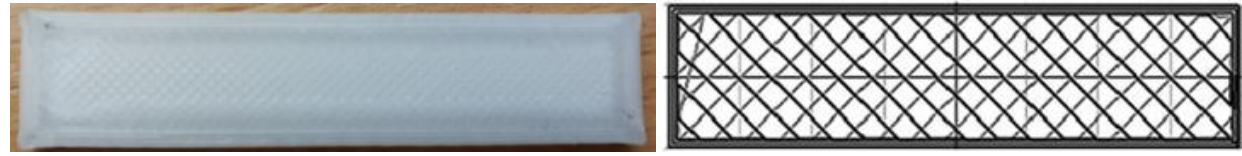

Fig. 1. (Color online) ) printed sample, b) rectilinear pattern model [25].

Figure 2 shows the thermograms of the first heating step of the filament produced by melt extrusion in a temperature range of $20^{\circ} \mathrm{C}$ to $200^{\circ} \mathrm{C}$. Table 3 presents the heating characteristics of the first heating step for the melt extrusion (ME) composites. Comparison with pure polymer matrix PLA (3D850) and the composites GNP/PLA and MWCNT/PLA filled with graphite (TNIGNP, aspect ratio D/Th $\sim 250$ ) as well as -OH modified multiwall carbon nanotubes (TNIMH4, aspect ratio, L/D > 1000).

"Black Magic" commercial filament based on graphite and carbon nanotubes PLA with 14 wt.\% filler was studied as a reference material.

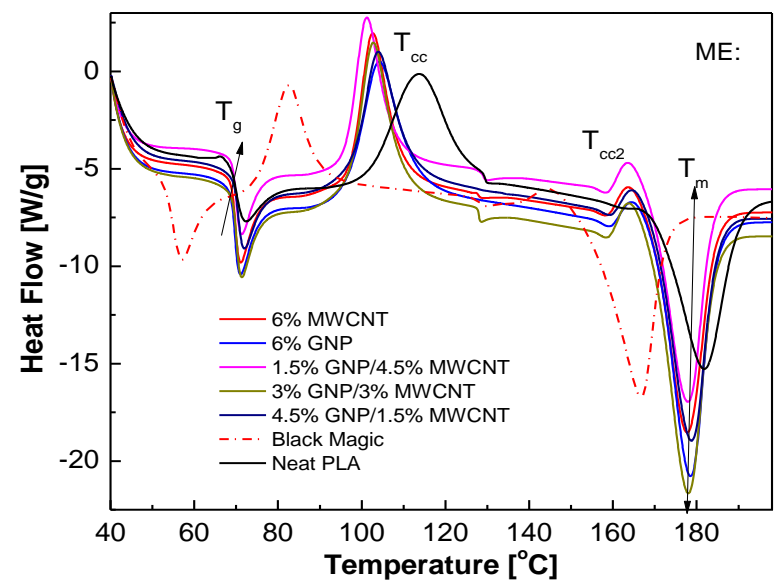

Fig. 2. (Color online) DSC curves - heat flow vs temperature for binary (GNP/PLA, MWCNT/PLA), ternary (GNP/MWCNT/PLA) nanocomposites and comercial filament Black Magic.

The results show that all nanocomposite formulation show a glass transition at $T_{g} \sim 70^{\circ} \mathrm{C}$, followed by a cold crystallisation $\left(T_{c c}\right)$ with significant enthalpy $\left(\Delta H_{c c}\right)$ followed by recrystallization $\left(T_{c c 2}\right)$ and melting $\left(T_{m}=178^{\circ} \mathrm{C}\right)$. The sharp drop in specific heat at $T_{g}$ loop is due to the absorbed moisture in the sample, which begins actively separating with heating. The glass transition temperature $\left(T_{g}\right)$ and the recrystallization temperature $\left(T_{c c 2}\right)$ remain without significant changes for all nanocomposites - i.e. they are not affected by the type or amount of added filler, 
Table 3. DSC crystallization of samples after melting at $200^{\circ} \mathrm{C}$ - calculated from first run for binary (GNP/PLA, MWCNT/PLA) and ternary (GNP/MWCNT/PLA) nanocomposites

\begin{tabular}{lcccccccccc}
\hline \hline \multirow{2}{*}{ Samples } & $T_{g}$ & $T_{c c}$ & $T_{c c 2}$ & $T_{m 1}$ & $T_{m}$ & $T_{c}$ & $\Delta H_{c}$ & $\Delta H_{c c}$ & $\Delta H_{m}$ & $\% \chi_{c}$ \\
& {$\left[{ }^{\circ} \mathrm{C}\right]$} & {$\left[{ }^{\circ} \mathrm{C}\right]$} & {$\left[{ }^{\circ} \mathrm{C}\right]$} & {$\left[{ }^{\circ} \mathrm{C}\right]$} & {$\left[{ }^{\circ} \mathrm{C}\right]$} & {$\left[{ }^{\circ} \mathrm{C}\right]$} & {$[\mathrm{J} / \mathrm{g}]$} & {$[\mathrm{J} / \mathrm{g}]$} & {$[\mathrm{J} / \mathrm{g}]$} & $(\mathrm{eq} .1)$ \\
\hline PLA & 70 & 114 & - & & 182 & - & - & 26 & 35 & 9 \\
$6 \%$ GNP & 70 & 104 & 165 & 159 & 179 & 106 & 27 & 23 & 37 & 17 \\
$6 \%$ MWCNT & 70 & 103 & 164 & 158 & 178 & 98 & 22 & 25 & 35 & 11 \\
$3 \%$ GNP/3\% MWCNT & 70 & 103 & 164 & 158 & 178 & 106 & 28 & 22 & 36 & 17 \\
4.5\% GNP/1.5\% MWCNT & 70 & 104 & 165 & 159 & 179 & 106 & 27 & 22 & 35 & 15 \\
1.5\% GNP/4.5\% MWCNT & 70 & 101 & 164 & 158 & 178 & 105 & 28 & 23 & 39 & 18 \\
Black Magic & 55 & 83 & 146 & 144 & 167 & 92 & 18 & 16 & 26 & 13 \\
\hline
\end{tabular}

nor whether the system is binary or ternary. The cold crystallization temperature $\left(T_{c c}\right)$ for the pure polymer matrix shows the highest value $\left(\sim 114^{\circ} \mathrm{C}\right)$, whereas for bi-component composites it decreases significantly by about $10^{\circ} \mathrm{C}$ and for the ternary system $1.5 \% \mathrm{GNP} / 4.5 \% \mathrm{MWCNT}$ it is the lowest $\sim 101^{\circ} \mathrm{C}$ ), which can be explained by the effect of carbon nanofillers on the recrystallization of PLA due to some nucleation effect of nanofillers on PLA, resulting in $\alpha^{\prime}-\alpha$ phase transition.

The degree of crystallinity is calculated (Eq. 1), and it is about 17-18\% for binary and ternary nanocomposites with GNP, whereas the 6\% MWCNT/PLA formulations have a lower crystallinity percentage $(11 \%)$, which is similar to that of the pure PLA

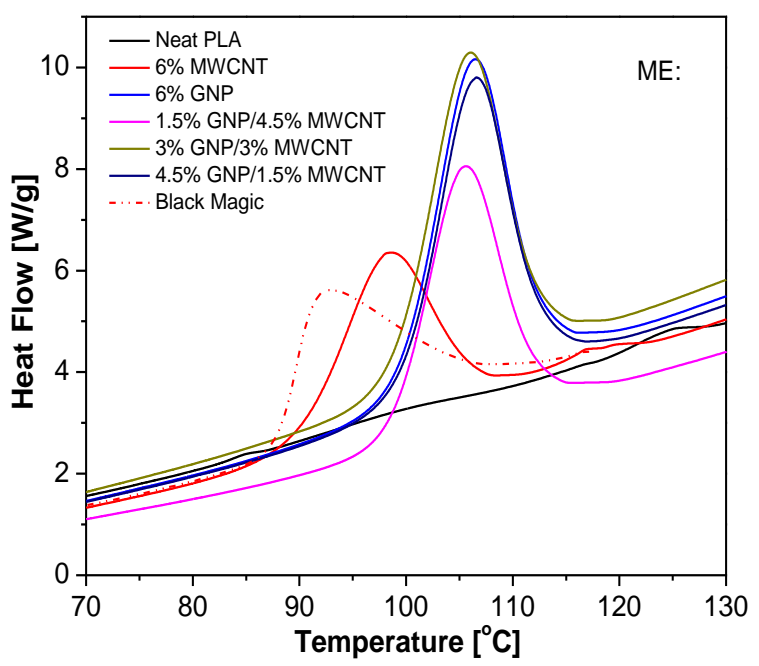

Fig. 3. (Color online) DSC curve shows the peak of crystallization from the cooling after the first heating step. 
matrix $(\sim 9 \%)$.

For comparison, for the Black Magic filament, these three characteristic temperatures $T_{g}, T_{c c}$ and $T_{m}$ are offset to the lower values by about $15^{\circ} \mathrm{C}$.

Figure 3 shows the heat flow versus temperature when the melt is cooled after the first heating step. From the graph and Table 3 it is clear that the pure PLA does not show a crystallization peak upon rapid melt cooling $\left(20^{\circ} \mathrm{C} / \mathrm{min}\right)$, i.e. it is amorphous. Whereas binary and ternary nanocomposites containing GNP follow the same tendency for crystallization peak at $T_{c} \sim 106^{\circ} \mathrm{C}$, i.e. they are semi-crystalline. An exception is the binary of $6 \%$ MWCNT, whose peak is with lower intensity and less enthalpy $\left(\Delta H_{c}\right)$ and is offset by $\sim 8^{\circ}$ to lower temperatures $\left(T_{c} \sim 98^{\circ}\right)$, compared to 6\% GNP. This effect may be related to the different nucleation effect of GNP and MWCNT, whereby GNP stimulates the crystallization kinetics of the PLA to a greater extent upon rapid cooling. This is probably due to the presence of sharp edges and a rough surface of the graphite layers that serve as germ-forming centers of PLA crystals, while nanotubes have a smooth surface.

Black Magic has the smallest crystallization peak around $13^{\circ} \mathrm{C}$ compared with all samples (Table 3).

\subsection{TGA ANALYSIS OF NANOCOMPOSITES}

Figure 4 shows TGA thermograms for mass loss (\%) vs first derivative of mass loss $\left(\% /{ }^{\circ} \mathrm{C}\right)$ as a function of temperature. They are compared with PLA (3D 850$)$, binary and ternary composites filled with industrial graphene (TNIGNP, aspect ratio, D/Th $\sim 240$ ) and -OH modified, multiwalled carbon nanotubes (TNIMH4, D > 1000). Table 4 presents the following thermal characteristics: Degradation Start Temperature ( $\left.T_{\text {onset }}\right)$; temperature at $10 \%$ loss of mass $\left(T_{10} \%\right)$, peak of degradation and residue ash

Table 4. The values of mass loss at $105^{\circ} \mathrm{C}$, peak of degradation and residue ash at $490^{\circ} \mathrm{C}$ for nanocomposite prepared by melt mixing method

\begin{tabular}{|c|c|c|c|c|c|}
\hline Samples & $\begin{array}{l}T_{\text {onset }} \\
{\left[{ }^{\circ} \mathrm{C}\right]}\end{array}$ & $\begin{array}{l}T_{10 \%} \\
{\left[{ }^{\circ} \mathrm{C}\right]}\end{array}$ & $\begin{array}{c}\text { Peak of } \\
\text { degradation } \\
{\left[{ }^{\circ} \mathrm{C}\right]}\end{array}$ & $\begin{array}{c}\text { Mass loss } \\
\text { at } 105^{\circ} \mathrm{C} \\
{[\%]}\end{array}$ & $\begin{array}{c}\text { Residue } \\
\text { ash at } 490^{\circ} \mathrm{C} \\
{[\%]}\end{array}$ \\
\hline PLA & 313.7 & 348.3 & 379.9 & 0.3 & 0.4 \\
\hline $6 \% \mathrm{GNP} / \mathrm{PLA}$ & 314.8 & 351.0 & 380.6 & 0.2 & 7.0 \\
\hline $6 \%$ MWCNT/PLA & 314.1 & 349.4 & 386.7 & 0.2 & 5.7 \\
\hline $1.5 \% \mathrm{GNP} / 4.5 \% \mathrm{MWCNT} / \mathrm{PLA}$ & 315.1 & 350.7 & 386.0 & 0.2 & 7.3 \\
\hline $3 \% \mathrm{GNP} / 3 \% \mathrm{MWCNT} / \mathrm{PLA}$ & 313.4 & 350.7 & 385.7 & 0.2 & 7.4 \\
\hline 4.5\%GNP/1.5\%MWCNT/PLA & 317.4 & 352.7 & 384.3 & 0.1 & 7.1 \\
\hline Black Magic & 316.5 & 334.6 & 386.12 & 0.3 & 15.1 \\
\hline
\end{tabular}




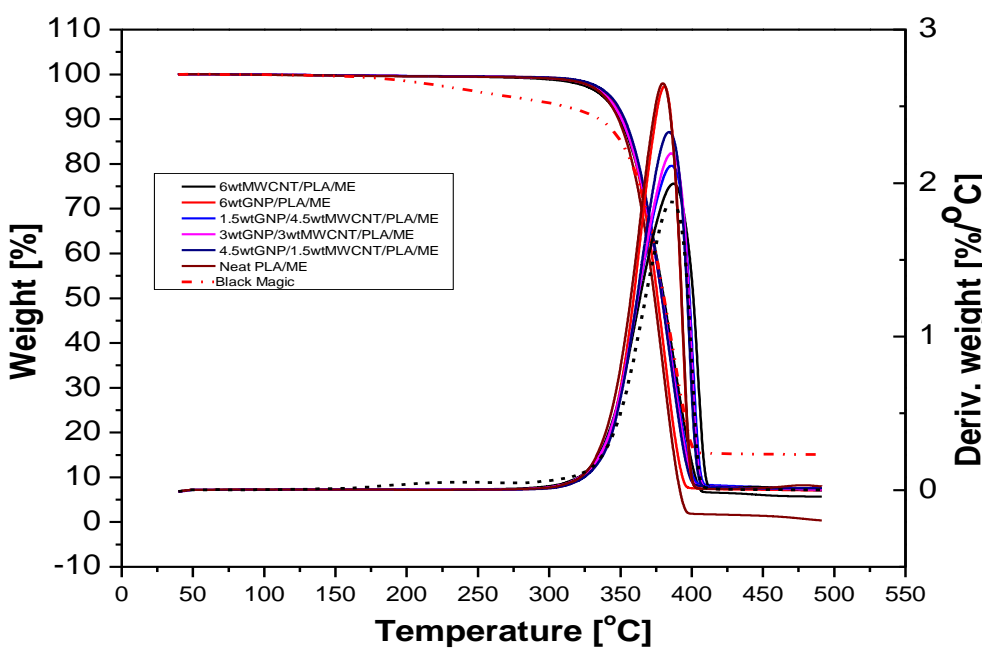

Fig. 4. (Color online) TGA curve weight vs temperature for nanocomposites with maximum of $6 \mathrm{wt} \%$ nanofiller (GNP, MWCNT and mixed) and comercial filament Black Magic.

at $490^{\circ} \mathrm{C}$ [\%] for melt extrusion composites (ME). The table shows also mass losses at $105^{\circ} \mathrm{C}$, from which can be estimated the amount of moisture absorbed.

The results show that all nanocomposites have similar values of thermal characteristics and the differences between these three temperatures are negligible. The ternary composite $4.5 \%$ GNP/1.5\% MWCNT/PLA has the best thermal stability but only with $4^{\circ} \mathrm{C}$ higher decomposition temperature (Tonset) and $10 \%$ loss of mass $\left(T_{10} \%\right)$ compared to pure PLA. Mass losses at $105^{\circ} \mathrm{C}$ are used to assess the amount of moisture absorbed. This composition also shows the lowest loss at $105^{\circ}$, i.e. the amount of absorbed moisture is small (0.1\%), compared to other compositions and PLA, where the mass losses at $105^{\circ} \mathrm{C}$ are $0.2-0.3 \%$. The amount of residual ash at $490^{\circ} \mathrm{C}$ for the nanocomposition is about $7 \%$, i.e. close to the percentage fill value while for the PLA it is $0.4 \%$. This indicates that the filler didn't degrade in the temperature of the measurement $\left(490^{\circ} \mathrm{C}\right)$, in which the pure PLA degrades completely. The commercial filament Black Magic has the lowest loss of mass $T_{10} \%$ but its decomposition temperature ( $\left.T_{\text {onset }}\right)$ is ony $1 \%$ lower than that of the ternaty nanocomposite $4.5 \%$ GNP $/ 1.5 \%$ MWCNT. The mass loss is around $0.3 \%$. This results can prouve that our materials have the same thermal stability but with only $6 \%$ of filler.

\subsection{DMTA ANALYSIS}

From DMTA analysis in torsion mode different parameters are defined - the storage modulus, the loss modulus and the tan(delta), which are an important characteristic 


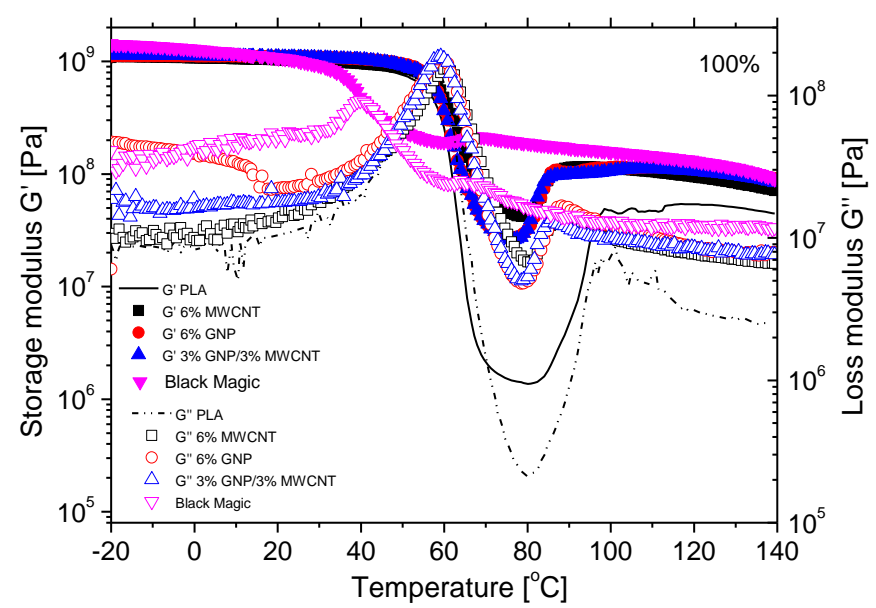

Fig. 5. (Color online) Storage modulus $G^{\prime}$, loss modulus $G^{\prime \prime}$ vs temperature for binary $6 \%$ GNP, 6\% MWCNT, ternary 3\% GNP/3\% MWCNT nanocomposites and comercial filament Black Magic compared with pure PLA matrix with $100 \%$ density.

for determining the mechanical properties of the composites.

Figure 5 shows the values of the storage modulus $G^{\prime}$ and the loss modulus $G^{\prime \prime}$, as a function of the temperature for binary composites $6 \%$ GNP/PLA, $6 \%$ MWCNT/PLA and ternary composite $3 \% \mathrm{GNP} / 3 \%$ MWCNT/PLA, compared to the pure polymeric matrix PLA for samples with a $100 \%$ density.

During the experiment we can determine three zones. The first is the zone $\left(-20^{\circ} \mathrm{C}\right.$ to $60^{\circ} \mathrm{C}$ ), where there are almost no changes in the sample. In this zone the sample is in a solid state. This zone is before the glass transition temperature $\left(T_{g}\right)$ and here the amorphous polymers are rigid and the storage modulus and loss modulus often are very high $-10^{9} \mathrm{~Pa}$. Also, the thermal energy is insufficient to overcome the potential bending barriers and the displacement of segments of the polymer molecules. The glass transition temperature is the temperature at which the polymer moves from a solid to a highly elastic state as a result of increased segmental mobility of the molecules. After $T_{g}\left(60^{\circ} \mathrm{C}\right.$ to $\left.100^{\circ} \mathrm{C}\right)$, there is a transition zone in which chain segments begin to move due to the increased heat energy. In this zone there is also a sharp drop in the values of the dynamic modules to $10^{5}-10^{6} \mathrm{~Pa}$. The third zone (above $100^{\circ} \mathrm{C}$ ) is called "Plateau" where the visco-elastic behavior of the material is observed. Because of the four order of the changing of moludus - between glass transition and elastic state, $T_{g}$ can be considered the most important characteristic of polymer material [27].

At lower temperatures range between $-20^{\circ} \mathrm{C}$ and $10^{\circ} \mathrm{C}$, in the solid state, the 
ternary nanocomposite $3 \% \mathrm{GNP} / 3 \%$ MWCNT has the highest storage modulus. After this temperature the binary composite $6 \%$ GNP exhibits better elasticity, which is maintained until the end of the temperature range (Fig. 6).

At $100 \%$ density, we have improved the storage modulus $G^{\prime}$ for the pure polymer matrix and for the ternary nanocomposite 3\% GNP/3\% MWCNT, but for the binary composites it decreases. For example, $6 \%$ graphene at an initial temperature of $20^{\circ} \mathrm{C}$ has a modulus of elasticity of $1.12 \mathrm{GPa}$ at $100 \%$ density. The commercial Black Magic in solid state has a higer initial temperature $1.44 \mathrm{GPa}$ but after $35^{\circ} \mathrm{C}$ the storage modulus decreases very strongly and keeps this tendency until to the end of the experiment.

The second temperature range is from $60^{\circ} \mathrm{C}$ to $90^{\circ} \mathrm{C}$ and is a transition area. Here the chain segments begins to break down as a result of the increase of the combustion energy. Within the range of $T_{g}$ at a temperature of $60^{\circ} \mathrm{C}$ to $90^{\circ} \mathrm{C}$, the $G^{\prime}$ and $G^{\prime \prime}$ composite values increase compared to the pure PLA, which is clear evidence of the better properties of the filler. Minimum values of both modules are minimized at $80-82^{\circ}$, which can be related to the so-called heat deflection temperature (HDT). It is important to note that the HDT values of the accumulation module are one decade higher than those of the pure PLA (Fig. 5).

The polymer matrix PLA has the lowest values for both modules - the storage modulus $\left(G^{\prime}\right)$ and the loss modulus $\left(G^{\prime \prime}\right)$ over the entire temperature range measured in a torsion mode. These two modules characterize the strength and plasticity of the polymeric material. After $60^{\circ} \mathrm{C}$ the values for both PLA modules drop drastically, which is a proof of the temperature transition from solid to visco-elastic state, i.e. glass transition temperature $\left(T_{g}\right)$ (Fig. 5).

At temperatures lower than $T_{g}$ (from $-20^{\circ} \mathrm{C}$ to $60^{\circ} \mathrm{C}$ ), i.e., when the material is in a solid state, the addition of a nanofiller, such as $6 \%$ graphene, results in an increase in storage modulus $G^{\prime}$ and loss modulus $G^{\prime \prime}$, which confirms the reinforcement effect of the nanofillers. As an example, in Table 5, the values for both the $G^{\prime}$ and $G^{\prime \prime}$ modules

Table 5. Storage modulus $G^{\prime}$, loss modulus $G^{\prime \prime}$, and tan(delta) at $20^{\circ} \mathrm{C}$

\begin{tabular}{|c|c|c|c|c|c|c|}
\hline Samples & $\begin{array}{l}\text { Storage } \\
\text { modulus } \\
G^{\prime}[\mathrm{GPa}]\end{array}$ & $\begin{array}{l}\text { Improv- } \\
\text { ement of } \\
G^{\prime}[\%]\end{array}$ & $\begin{array}{c}\text { Loss } \\
\text { modulus } \\
G^{\prime \prime}[\mathrm{GPa}] \\
\end{array}$ & $\begin{array}{c}\text { Improv- } \\
\text { ement of } \\
G^{\prime \prime}[\%]\end{array}$ & $\begin{array}{c}\text { Tan(delta) } \\
100 \% \\
\text { density } \\
\end{array}$ & $\begin{array}{c}\text { Half-width of } \\
\text { the } \tan (\text { delta) } \\
\text { peak }\left[{ }^{\circ} \mathrm{C}\right]\end{array}$ \\
\hline PLA & 0.95 & - & 0.010 & - & 2.90 & 6.8 \\
\hline $6 \%$ GNP & 1.11 & 17 & 0.022 & 119 & 0.86 & 11.67 \\
\hline $6 \% \mathrm{MWCNT}$ & 1.03 & 8 & 0.015 & 47 & 0.57 & 9.55 \\
\hline $3 \%$ GNP/3\%MWCNT & 1.10 & 16 & 0.018 & 74 & 0.75 & 12.83 \\
\hline Black Magic & 1.07 & & 0.052 & & 0.05 & 15.58 \\
\hline
\end{tabular}


252 Mechanical and Thermal Properties of PLA Based Nanocomposites with ...

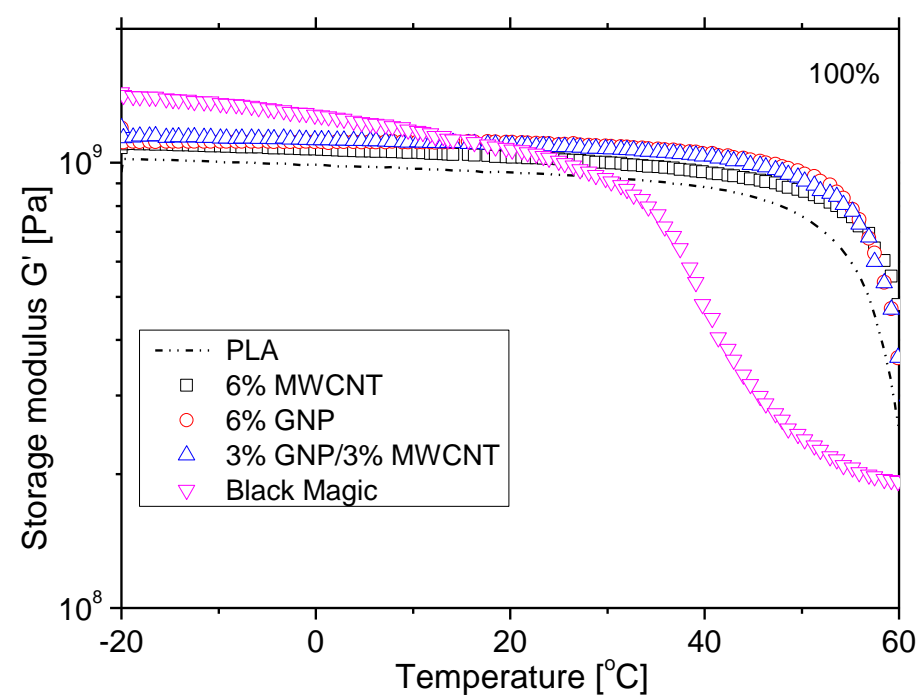

Fig. 6. (Color online) Storage modulus $G^{\prime}$ vs temperature from $-20^{\circ} \mathrm{C}$ to $60^{\circ} \mathrm{C}$ for binary $6 \%$ GNP, $6 \%$ MWCNT, ternary $3 \%$ GNP/3\% MWCNT nanocomposites and comercial filament Black Magic compared with pure PLA matrix with $100 \%$ density.

are presented at room temperature of $20^{\circ} \mathrm{C}$, and the percentage of improvement of the two modules compared with pure PLA is calculated. For the binary nanocomposite with $6 \%$ GNP, the elasticity $\left(G^{\prime}\right)$ improved by $17 \%$ and the plasticity $\left(G^{\prime \prime}\right)$ by $119 \%$ at $100 \%$ printing density.

For the ternary nanocomposite 3\% GNP/3\% MWCNT, there was also an increase in the values of the modulus in solide state in the low temperature zone, due to the reinforcing effect of the graphene nanoparticles (Fig. 6).

Figure 7 shows $\tan ($ delta) as a function of the temperature for the binary nanocomposites $6 \%$ GNP, $6 \%$ MWCNT, ternary nanocomposites 3\% GNP/3\% MWCNT and

Table 6. Glass transition $\left(T_{g}\right)$ from DMTA and DSC analysis

\begin{tabular}{lccc}
\hline \hline Samples & $\begin{array}{c}T_{g},\left[{ }^{\circ} \mathrm{C}\right] \\
(\mathrm{DMTA})\end{array}$ & $\begin{array}{c}T_{g},\left[{ }^{\circ} \mathrm{C}\right] \\
(\mathrm{DSC})\end{array}$ & $\begin{array}{c}\% \chi_{c} \\
(\mathrm{DSC})\end{array}$ \\
\hline PLA & 65.5 & 66.0 & 9.2 \\
$6 \%$ GNP & 64.0 & 67.4 & 16.7 \\
$6 \%$ MWCNT & 65.0 & 67.6 & 10.5 \\
3\%GNP/3\% MWCNT & 63.4 & 66.9 & 16.7 \\
Black Magic & 43.0 & 55.1 & 12.5 \\
\hline
\end{tabular}




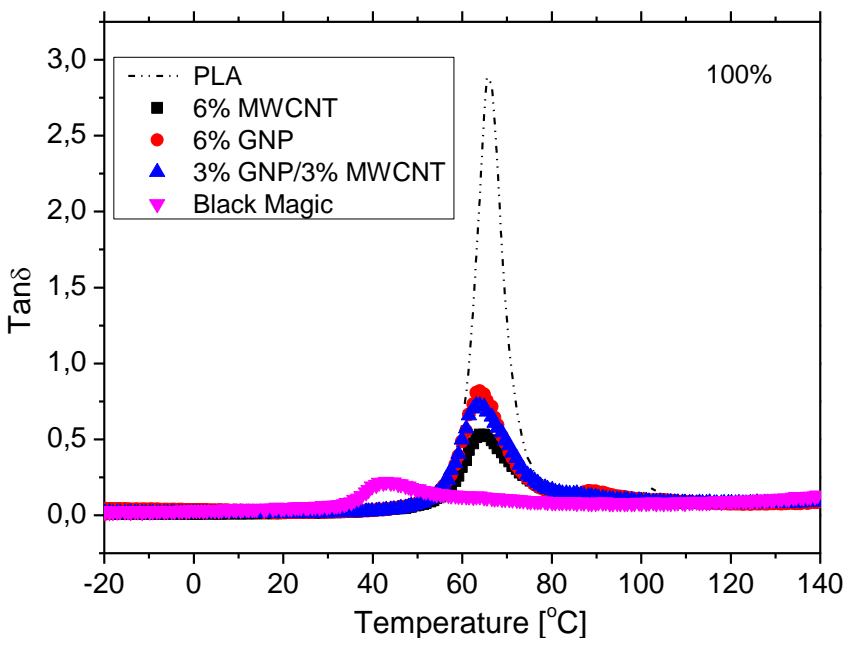

Fig. 7. (Color online) Tan(delta) vs temperature for PLA, 6\% GNP, 6\% MWCNT, $3 \% \mathrm{GNP} / 3 \%$ MWCNT and commercial filament Black Magic, 100\% density.

benchmark Black Magic. The peak of tan(delta) is associated with the glass transition temperature of the material. Table 6 compares the glass transition temperature $T g$ determined by the DMTA analysis and the DSC analysis.

Tan(delta) $=G^{\prime \prime} / G^{\prime}$, then the high value of delta $=3$ in the peak area for PLA indicates that the pure polymer is a rather plastic material with values for $G^{\prime \prime} \gg G^{\prime}$. While adding a nanofiller reduces the value of $\tan ($ delta $)<1$, i.e. the material become more elastic, modulus of elasticity is higher than that of plasticity. This shows that the composite material is stronger but much more fragile than the pure PLA.

The glass transition temperature $\left(T_{g}\right)$ determined from the peak of tan(delta) at the DMTA analysis compared to that determined by the DSC analysis is shown in Table 6. $T_{g}$ varies within very small limits of $2-3^{\circ} \mathrm{C}$; the nanocomposite values determined by DMTA are lower than those determined by the thermal analysis. This small difference in glass transition temperatures may be due to the different heat rates in both experiments (for DMTA analysis at $3^{\circ} \mathrm{C} / \mathrm{min}$ and for DSC analysis at $20^{\circ} \mathrm{C} / \mathrm{min}$ ). But, the effect of the different types of fillers, GNP, MWCNT, and mixed filler, on the value of $\tan ($ delta) peak of temperature, is negligible.

The polymer matrix has a glass transition temperature of about $66^{\circ} \mathrm{C}$, as well as the highest intensity of $\tan$ (delta) 2.9 , but also the lowest crystallinity of $9.2 \%$. High intensity, small half-width and low crystallinity are a hallmark of amorphous polymers, which confirms the nature of the polymer matrix used (Fig. 7). Increasing the crystallinity also increases $T_{g}$. The highest crystallinity rate of $16.7 \%$ is for ternary 
nanocomposite 3\% GNP/3\% MWCNT and the binary nanocomposite 6\% GNP, the half-width of which is the greatest. With the addition of $6 \%$ of the nanofiller, the crystallinity increases and the intensity decreases in proportion to the crystallinity. These indexes confirm the higher value of the modulus of elasticity $G^{\prime}$ of the binary nanocomposite with graphene and of the ternary nanocomposite compared to the same amount of multiwalled carbon nanotubes.

According to the DMTA analysis Black Magic with $14 \%$ filler has a $20^{\circ} \mathrm{C}$ lower glass transition temperature compered with our samples. This confirms the better properties of our samples with only $6 \%$ of filler and is a proof of the better elasticity and thermal stability of our samples.

\section{CONClusion}

The composite with graphite $6 \%$ GNP/PLA as well as ternary composites have a higher crystallinity percentage (17-18\%) compared to PLA (9\%). The crystallinity of all nanocomposites increases to semicrystalline materials after thermal treatment to $200^{\circ} \mathrm{C}$ and rapid cooling at $20^{\circ} \mathrm{C} / \mathrm{min}$. This is explained by the nuclear effect of carbon nanofiller on PLA.

All composites have a similar thermal stability that is close to that of pure polymer PLA. The amount of residual ash at $490^{\circ} \mathrm{C}$ for these nanocomposites is about $7 \%$, i.e. similar to the content of the filler in the polymer. Therefore, the carbon nanofiller does not degrade under these thermal treatment conditions while the pure PLA degrades completely.

With the addition of $6 \%$ graphene, a higher crystallinity is achieved this resulting in the highest modulus of elasticity $G^{\prime}$ in the solid state temperature range. From this it can be concluded that the modulus of elasticity $G^{\prime}$ is influenced by the percentage of crystallinity of the PLA-based composite material. Graphene nanofiller has a more significant strengthening effect than multiwalled carbon nanotubes on storage modulus $G^{\prime}$ in solid-state as well as on tan(delta) peak.

With only $6 \%$ filler we obtain $15^{\circ} \mathrm{C}$ higher glass transition temperature, crystallization and melting temperature. Decomposition temperature and thermal stability show better behavior for $6 \%$ GNP compared to Black Magic. Storage modulus and loss modulus are improved by adding 6\% GNP. This commercial material shows the worst elasticity and plasticity of mechanical point of view. Storage modulus $G^{\prime}$ in solid state for Black Magic strongly derceases after $35^{\circ} \mathrm{C}$ until the end of process compared with $6 \%$ GNP which starts to decrease after $80^{\circ} \mathrm{C}$ (Fig. 5, Table 5). Tan(delta) peak also decreases with 0.86 for $6 \%$ GNP and 2.9 for pure PLA (Table 5).

From these results we can conclude that our materials show better results for thermal stability and mechanical properties compared to the benchmark Black Magic. 


\section{ACKNOWLEDGEMENTS}

This work was supported by the European projects H2020-MSCA-RISE-2016-734164 Graphene 3D and H2020-SGA-FET-GRAPHENE-2017-785219 Graphene Core 2.

\section{REFERENCES}

[1] Y. Gao, O. Picot, E. Bilotti, T. Peiss (2017) Influence of Filler Size on the Properties of Poly(Lactic Acid) (PLA)/Graphene Nanoplatelet (GNP) Nanocomposites. European Polymer Journal 86 117-131.

[2] K. Anderson, K. Schreck, M. Hillmyer (2008) Toughening Polylactide. Polymer Reviews 48(1) 85-108.

[3] J. MARK (2009) "Polymer Data Handbook". Oxford University Press, London, p. 1264.

[4] J. Raquez, Y. Habibi, M. Murariu, P. Dubois (2013) Polylactide (PLA)-Based Nanocomposites. Progress in Polymer Science 38(10-11) 1504-1542.

[5] R. Bhardwaj, A. Mohanty (2007) Advances in the Properties of Polylactides Based Materials: A Review. Journal of Biobased Materials and Bioenergy 1(2) 191-209.

[6] M. Murariu, A.-L. Dechief, R. Ramy-Ratiarison, Y. Paint, J.-M. Raquez, P. Dubois (2015) Recent Advances in Production Of Poly (Lactic Acid) (PLA) Nanocomposites: A Versatile Method to Tune Crystallization Properties of PLA. Nanocomposites 1(2) 71-82.

[7] H. Kim, A. Abdala, C. Macosko (2010) Graphene/Polymer Nanocomposites. Macromolecules 43(16) 6515-6530.

[8] K. Sadasivuni, D. Ponnamma, S. Thomas, Y. Grohens (2014) Evolution from Graphite to Graphene Elastomer Composites. Progress in Polymer Science 39(4) 749780.

[9] J. Xu, T. Chen, C. Yang, Z. Li, Y. MaO, B. Zeng, B. HsiaO (2010) Isothermal Crystallization of Poly(L-Lactide) Induced by Graphene Nanosheets and Carbon Nanotubes: A Comparative Study. Macromolecules 43(11) 5000-5008.

[10] Y. Sun, C. He (2012) Synthesis and Stereocomplex Crystallization of Poly (Lactide)Graphene Oxide Nanocomposites. ACS Macro Letters 1(6) 709-713.

[11] Y. XU, W. Hong, H. BAI, C. LI, G. SHI (2009) Strong and Ductile Poly(Vinyl Alcohol)/Graphene Oxide Composite Films with a Layered Structure. Carbon 47(15) 35383543.

[12] A. Nuona, X. Li, X. Zhu, Y. Xiao, J. Che (2015) Starch/Polylactide Sustainable Composites: Interface Tailoring with Graphene Oxide. Composites Part A: Applied Science and Manufacturing 69 247-254.

[13] J.Y. NAm, S. Sinha RaY, M. OKamoto (2003) Crystallization Behavior and Morphology of Biodegradable Polylactide/Layered Silicate Nanocomposite. Macromolecules 36(19) 7126-7131.

[14] H. WANG, Z. QIU (2012) Crystallization Kinetics and Morphology of Biodegradable Poly(L-Lactic Acid)/Graphene Oxide Nanocomposites: Influences of Graphene Oxide Loading and Crystallization Temperature. Thermochimica Acta 527 40-46. 
256 Mechanical and Thermal Properties of PLA Based Nanocomposites with ...

[15] Y. Fu, L. LiU, J. Zhang, W.C. Hiscox (2014) Functionalized Graphenes with Polymer Toughener as Novel Interface Modifier for Property-Tailored Polylactic Acid/Graphene Nanocomposites. Polymer (UK) 55(24) 6381-6389.

[16] Y. FU, L. LiU, J. ZHANG (2014) Manipulating Dispersion and Distribution of Graphene in PLA through Novel Interface Engineering for Improved Conductive Properties. ACS Applied Materials \& Interfaces 6(16) 14069-14075.

[17] Y. Shen, T. Jing, W. Ren, J. Zhang, Z.G. Jiang, Z. Yu, A. DASARI (2012) Chemical and Thermal Reduction of Graphene Oxide and Its Electrically Conductive Polylactic Acid Nanocomposites. Composites Science and Technology 72(12) 14301435.

[18] B. Mortazavi, F. Hassouna, A. Laachachi, A. Rajabpour, S. Ahzi, D. Chapron, V. Toniazzo, D. Ruch (2013) Experimental and Multiscale Modeling of Thermal Conductivity and Elastic Properties of PLA/Expanded Graphite Polymer Nanocomposites. Thermochimica Acta 552 106-113.

[19] I.-H. Kim, Y.G. JeONG (2010) Polylactide/Exfoliated Graphite Nanocomposites with Enhanced Thermal Stability, Mechanical Modulus, and Electrical Conductivity. Journal of Polymer Science Part B: Polymer Physics 48(8) 850-858.

[20] L. LeI, J. QIU, E. SAKaI (2012) Preparing Conductive Poly(Lactic Acid) (PLA) with Poly(Methyl Methacrylate) (PMMA) Functionalized Graphene (PFG) by Admicellar Polymerization. Chemical Engineering Journal 209 20-27.

[21] X.-Z. Tong, F. Song, M.-Q. LI, X.-L. WANG, I.-J. Chin, Y.-Z. WANG (2013) Fabrication of Graphene/Polylactide Nanocomposites with Improved Properties. Composites Science and Technology 88 33-38.

[22] B.W. Chieng, N.A. Ibrahim, W.M. Yunus, M.Z. Hussein, Y.Y. Then, Y.Y. LOO (2015) Reinforcement of Graphene Nanoplatelets on Plasticized Poly(Lactic Acid) Nanocomposites: Mechanical, Thermal, Morphology, and Antibacterial Properties. Journal of Applied Polymer Science 132(11).

[23] L. Zhang, Y. Li, H. Wang, Y. QiaO, J. Chen, S. CaO (2015) Strong and Ductile Poly(Lactic Acid) Nanocomposite Films Reinforced with Alkylated Grapheme Nanosheets. Chemical Engineering Journal 264 538-546.

[24] Y. Jin, J. WAng, H. Ke, S. WAng, Z. DAi (2013) Graphene Oxide Modified PLA Microcapsules Containing Gold Nanoparticles for Ultrasonic/CT Bimodal Imaging Guided Photothermal Tumor Therapy. Biomaterials 34(20) 4794-4802.

[25] M. Fernandez-Vincente, W. Calle, S. Ferrandiz, A.Conejero (2016) Effect of Infill Parameters on Tensile Mechanical Behavior in Desktop 3D Printing. 3D Printing and Additive Manufacturing 3(3); DOI: 10.1089/3dp.2015.0036.

[26] I. Armentano, E. Fortunatu, N. Burgos, F. Dominici, F. Luzi, S. Fiori, A. Jimenez, K. Yoon, J. Ahn, S. Kang, J. Kenny (2015) Processing and Characterization of Plasticized PLA/PHB Blends for Biodegradable Multiphase System. Express Polymer Letters 9(7) 583-596.

[27] www.uab.edu/engineering/home/images/downloads/Practical_Rheology_Workshop_UAB.pdf 